\title{
Branding UMKM untuk Meningkatkan Potensi Promosi dan Penjualan Secara Mandiri
}

\author{
Syarifah Fadillah Rezky ${ }^{1}$, Rita Hamdani ${ }^{2}$, Devri Suherdi ${ }^{3}$, \\ Kamil Erwansyah $^{4}$, Erika Fahmi Ginting ${ }^{5}$, Pandi Barita Nauli Simangunsong ${ }^{6}$ \\ ${ }^{12345}$ Sistem Informasi, STMIK Triguna Dharma \\ ${ }^{6}$ Teknik Informatika, Politeknik LP3I Medan
}

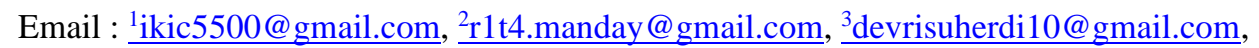
4erwansyah.kamil@gmail.com, 5 erikafg04@gmail.com,

\begin{abstract}
Abstrak
Branding packaging merupakan salah satu cara untuk memikat calon konsumen UMKM dalam menentukan keputusan untuk membeli produk UMKM. Masih banyak pelaku UMKM yang tidak faham mengenai fungsi branding dan menciptakan branding produk mereka. Dari hasil survey angket yang kami berikan kepada pelaku UMKM di Binjai yang tergabung dalam organisasi IWAPI (Ikatan Wanita Pengusaha Indonesia) $79 \%$ belum memahami peran branding produk khususnya sebagai cirikhas produk UMKM, untuk dapat bersaing dipasar global maka UMKM harus terus berinovasi dan mengembangkan produk mereka. Melalui kegiatan pengabdian Masyarakat ini memberi motivasi dan pengetahuan kepada pelaku UMKM khususnya di Binjai. Tujuan dari pengabdian ini selain memotivasi dan memberi sosialisasi kepada pelaku UMKM mengenai peran branding packaging dalam meningkatkan penjualan juga sebagai media promosi digital kepada konsumen, serta sinergi kegiatan pengabdian masyarakat yang dilakukan oleh akademisi. Metode yang digunakan dalam pengabdian ini bersifat diskusi, ceramah dan praktik branding digital secara visual.
\end{abstract}

Kata kunci: Branding, Packaging, Promosi, Penjualan, UMKM.

\begin{abstract}
Branding packaging is one way to attract potential UMKM consumers in determining the decision to buy UMKM products. There are still many UMKM actors who do not understand the function of branding and create branding for their products. From the results of the questionnaire survey that we gave to UMKM actors in Binjai who are members of the IWAPI organization (Indonesian Women Entrepreneurs Association) $79 \%$ do not understand the role of product branding, especially as a characteristic of MSME products, to be able to compete in the global market, UMKM must continue to innovate and develop its products. Through this community service activity, it provides motivation and knowledge to UMKM actors, especially in Binjai. The purpose of this service is to motivate and provide socialization to UMKM actors regarding the role of branding packaging in increasing sales and digital promotion media to consumers, as well as the synergy of community service activities carried out by academics. The methods used in this service are discussions, lectures and the practice of visual digital branding.
\end{abstract}

Keywords: Branding, Packaging, Promotion, Sales, UMKM.

\section{PENDAHULUAN}

Usaha mikro kecil dan menengah (UMKM) memiliki peran dalam mempertahankan roda perekonomian nasional. Pemerintah saat ini sedang gencar untuk membuat UMKM naik kelas dengan berbagai program yang diberikan kepada pelaku UMKM, baik modal usaha, pelatihan serta pendampingan usaha dengan stakeholder(Arianto, 2019).

UMKM merupakan usaha dagang yang dikelola secara perorangan maupun badan usaha yang memiliki lingkup usaha mikro (Entrepreneurial Mindsets \& Skill - Hadion Wijoyo - Google Buku, n.d.). UMKM di Binjai khususnya yang tergabung dalam organisasi IWAPI (ikatan wanita pengusaha Indonesia) memiliki berbagai latar belakang usaha baik kuliner, riteling, produk kesehatan herbal, furniture, dan Laundry. Berdasarkan hasil survey angket yang dilakukan 79\% Pelaku UMKM di Binjai 
masih banyak yang belum memahami dan membangun branding produk mereka. Branding merupakan istilah dari sebuah nama, symbol dan perancangan sebuah desain pada produk (Irawan \& Affan, 2020). UMKM harus berinovasi agar dapat bersaing secara global. Banyak cara yang dapat dilakukan pelaku UMKM untuk dapat bersaing dengan kompetitor sejenis, yaitu dengan meningkatkan mutu produk, desain dan branding produk, pemanfaatan teknologi dalam pemasaran produk, serta survey kepuasan konsumen (Irvan, 2015).

Produk yang bagus tanpa Branding packaging yang baik serta strategi pemasaran akan sia sia. Branding packaging juga dapat menjadi media promosi kepada konsumen, branding yang memiliki ciri khas menjadi brain minded kepada konstumer. Ciri khas dapat berupa logo, desain kemasan, pewarnaan, serta tipografi(Setiawati, 2019). Pelaku UMKM di Binjai khususnya yang tegabung dalam IWAPI (Ikatan Wanita Pengusaha Indonesia)memiliki beberapa masalah dalam mengembangkan branding produk mereka yaitu belum memahami apa itu branding dan manfaatnya. Belum pernah memiliki pendampingan branding produk UMKM, serta jiwa saing sebagai enterprenuer masih belum maksimal.

Dengan melihat dan mengacu pada permasalahan tersebut maka Civitas Akademika STMIK Triguna Dharma yang terdiri dari dosen dan mahasiswa melakukan pengabdian masyarakat dalam bentuk diskusi dan narasumber dalam kegiatan sosialisasi Branding UMKM dengan tujuan memberikan pemahaman kepada pelaku UMKM mengenai peran dari Branding produk dalam mengembangkan usaha dan meningkatkan penjualan, sehingga memotivasi pelaku UMKM untuk berinovasi dan memiliki branding produk yang baik. Konsumen yang merasa puas akan produk yang dihasilkan oleh Pelaku UMKM dengan sendirinya akan melakukan marketing dari mulut (word of mouth marketing) kepada calon konsumen lainnya.

\section{METODE PELAKSANAAN}

Adapun metode pelaksanaan dalam pengabdian masyarakat ini menggunakan metode diskusi dan ceramah oleh narasumber. Diskusi bersifat terbuka dengan para pelaku UMKM di kota Binjai khususnya yang tergabung dalam organisasi IWAPI (Ikatan Wanita Pengusaha Indonesia).

\subsection{Waktu Pelaksanaan}

Pengabdian ini dilaksanakan oleh Civitas Akademisi STMIK Triguna Dharma yang terdiri dari Dosen dan Mahasiswa. Dilaksanakan pada bulan Juli 2021 berlokasi di Aula Serba guna Walikota Binjai.

\subsection{Peserta}

Peserta yang mengikuti kegiatan pengabdian masyarakat ini terdiri dari pelaku UMKM di binjai khususnya anggota organisasi IWAPI. Pelaku UMKM memiliki berbagai jenis latar belakang bidang usaha baik kuliner, ritel, produk kesehatan, furnitur, dan laundry.

\subsection{Tahapan Kegiatan}

Kegiatan pengabdian ini terdiri dari beberapa tahap yaitu:

1. Melakukan observasi lapangan berupa pengumpulan informasi jenis usaha para Pelaku UMKM dan pengelompokkan produk UMKM.

2. Melakukan sosialisasi branding UMKM dalam bentuk pemaparan dari narasumber serta diskusi bersifat terbuka kepada Pelaku UMKM.

3. Memberikan masukkan terhadap branding pelaku UMKM dan memberikan contoh branding usaha kekinian.

\section{HASIL DAN PEMBAHASAN}

Adapun hasil dari pengabdian ini berupa sosialisasi brand UMKM yang dilakukan oleh narasumber kepada pelaku UMKM materi pembahasan terdiri dari Desain Kemasan, peran logo dalam branding, pemasaran produk dengan pemanfaatan media sosial, dan proses sertifikasi produk halal. 
Dalam kegiatan pengabdian masyarakat ini narasumber memberikan pemahaman dan motivasi kepada pelaku UMKM mengenai pentingnya branding UMKM. Dari hasil survey yang kami lakukan terdapat 79\% pelaku UMKM di binjai khususnya anggota organisasi IWAPI belum memahami peran branding produk. Narasumber memberikan konsultasi dan diskusi secara terbuka kepada pelaku UMKM dan bedah desain produk UMKM guna memberikan masukkan dalam branding produk.

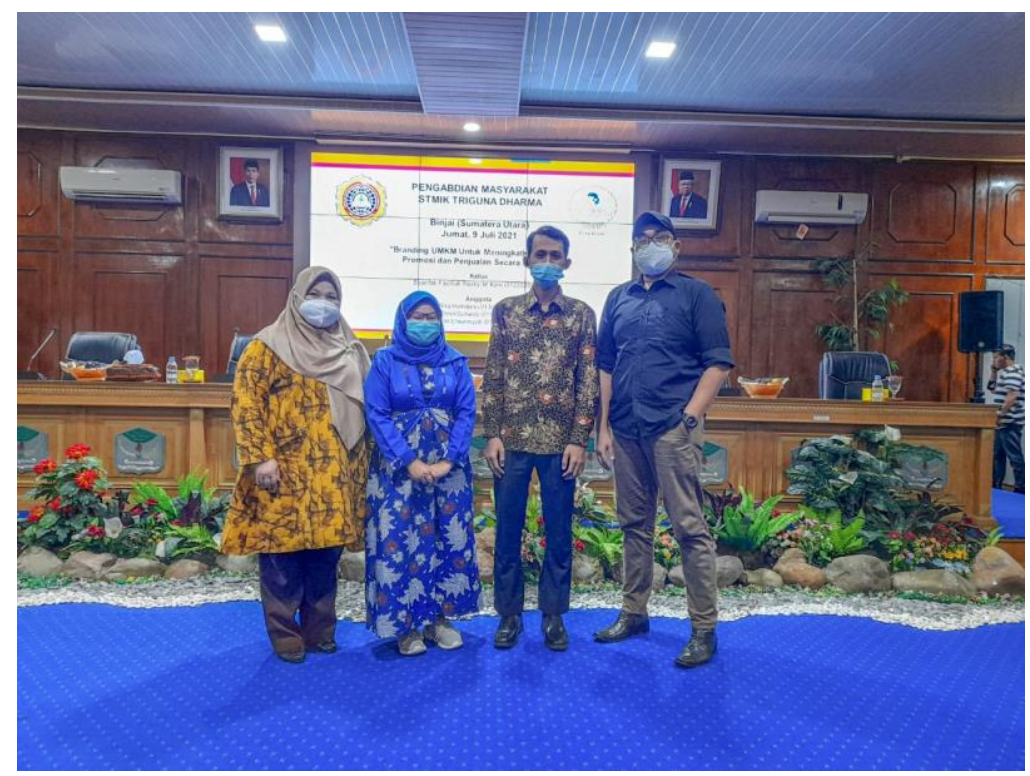

Gambar 1. Tim Pengabdian masyarakat

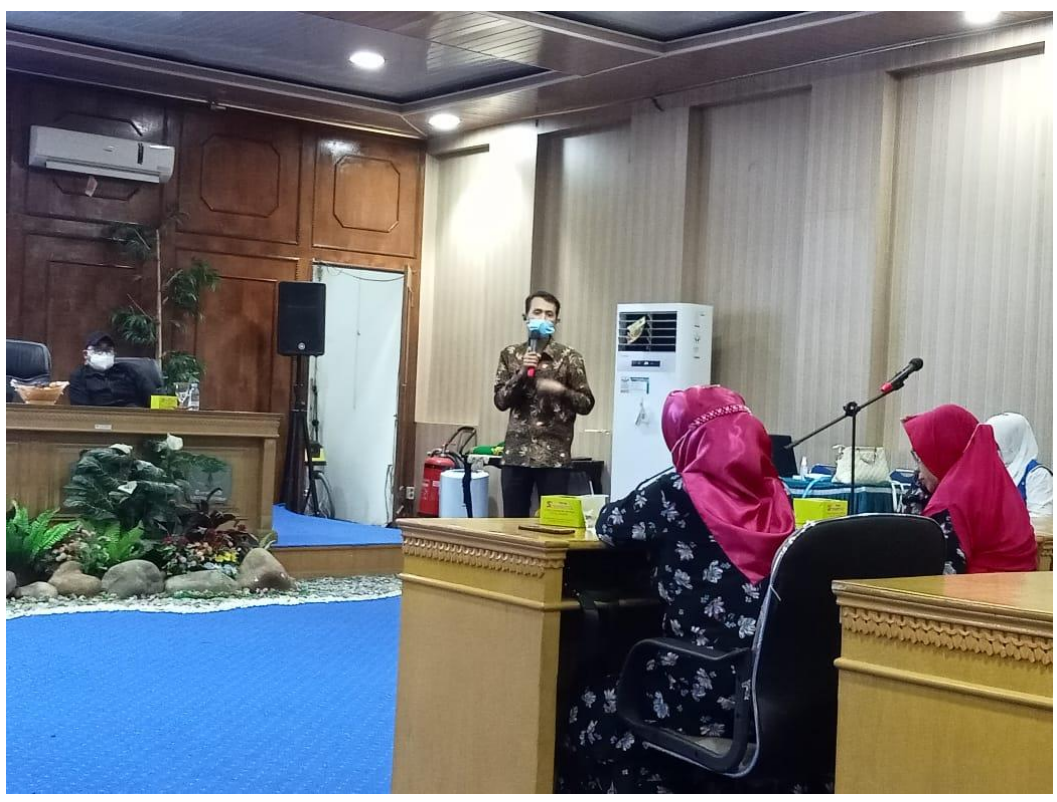

Gambar 2. Pemaparan Materi oleh Narasumber 


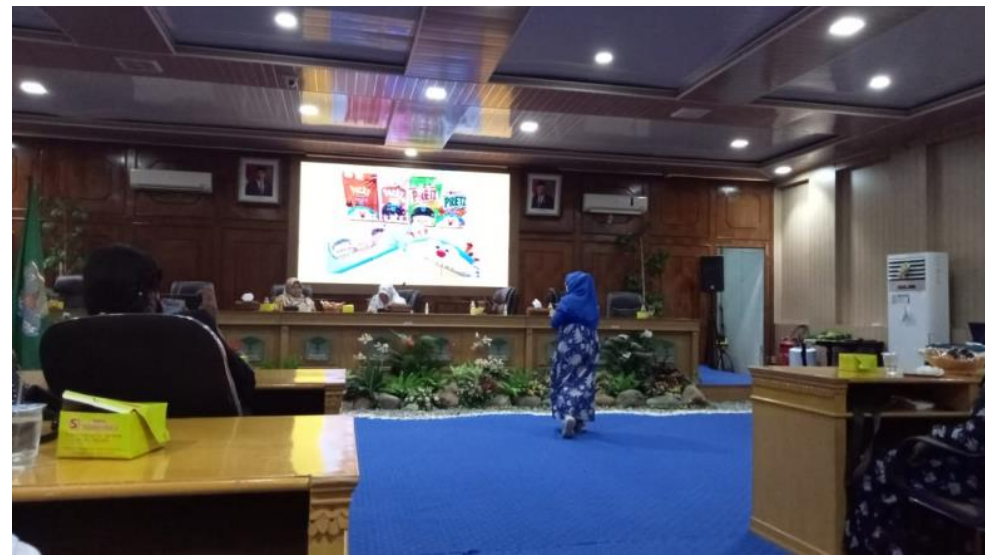

Gambar 3. Bedah Branding Produk dan diskusi kepada Pelaku UMKM

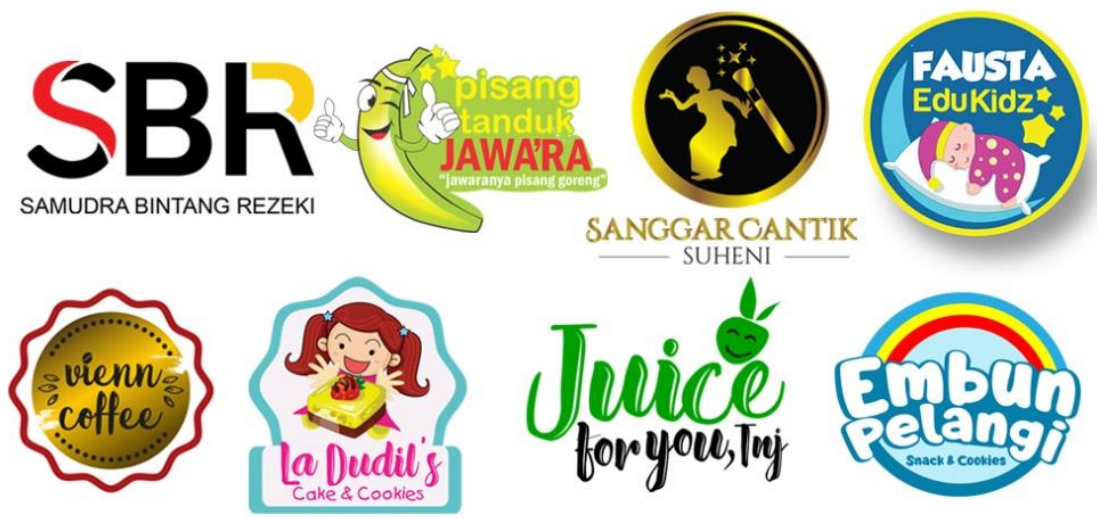

Gambar 4. Contoh dari bedah branding logo UMKM

Dari hasil sosialisasi Brand UMKM ini kami merangkum umpan balik yang dilakukan oleh pelaku UMKM dengan hasil sebagai berikut.

Hasil rekapitulasi angket $79 \%$ pelaku UMKM Sangat minim pemahaman akan Peran dari branding produk.

\section{Apakah Anda Memahami Arti Branding Produk}

$\square$ Tidak Mengerti $\square$ Mengerti $\square$ Cukup Mengerti $\square$ Sangat Mengerti

$5 \% \quad 0 \%$

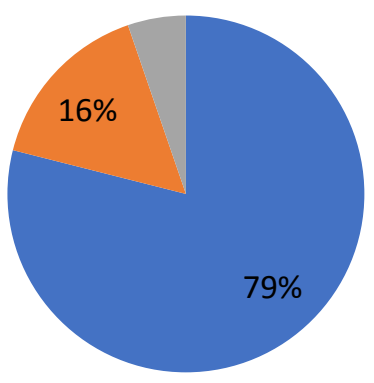

Gambar 5. Umpan balik pelaku UMKM mengenai arti branding produk 
Sebanyak $63 \%$ didominasi pelaku UMKM yang belum mengerti akan dampak desain kemasan dan logo terhadap promosi produk mereka.

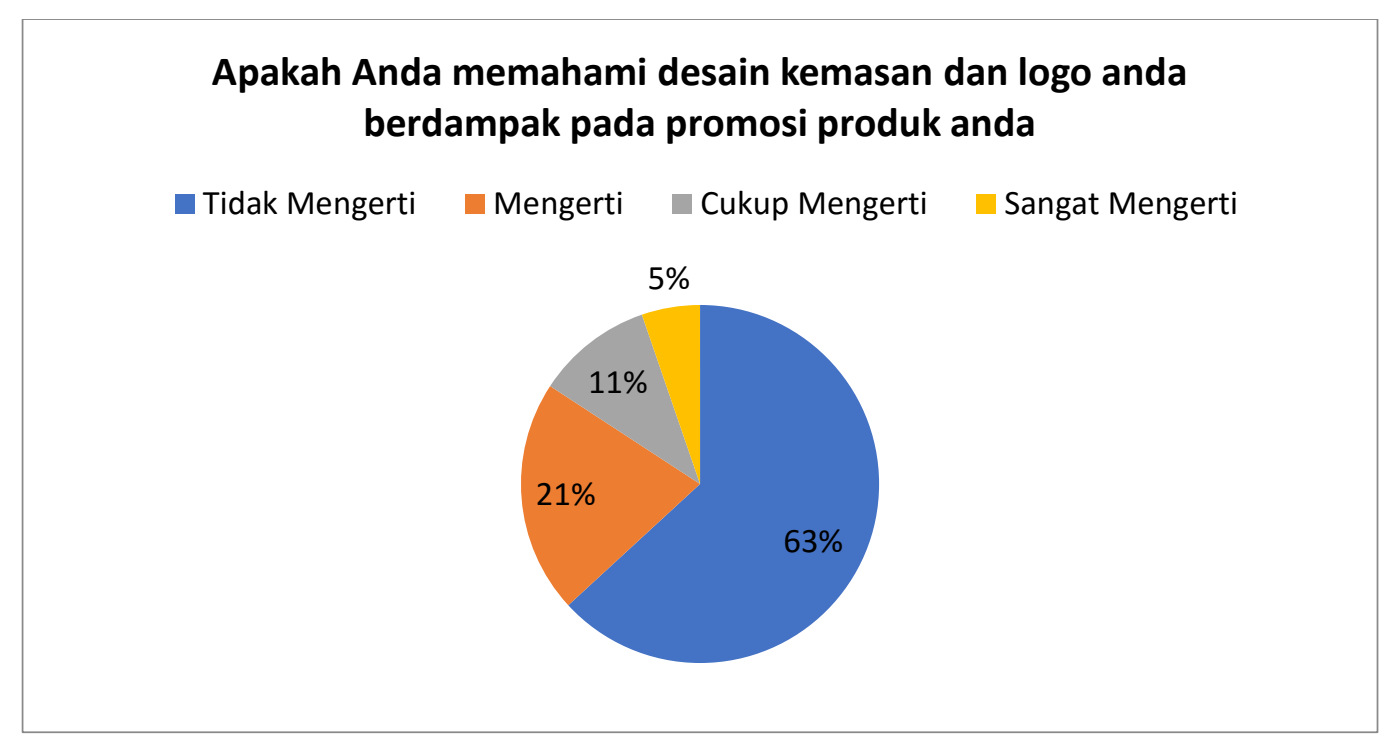

Gambar 6. Umpan balik pelaku UMKM mengenai dampak dari branding terhadap promosi produk

Setelah mengikuti sosialisasi Branding UMKM dari kegiatan pengabdian Masyarakat ini, sebanyak 45\% Pelaku UMKM Sangat mengerti dan 39\% mengerti akan peran daripada Branding produk UMKM sebagai brain mainded produk kepada kostumer.

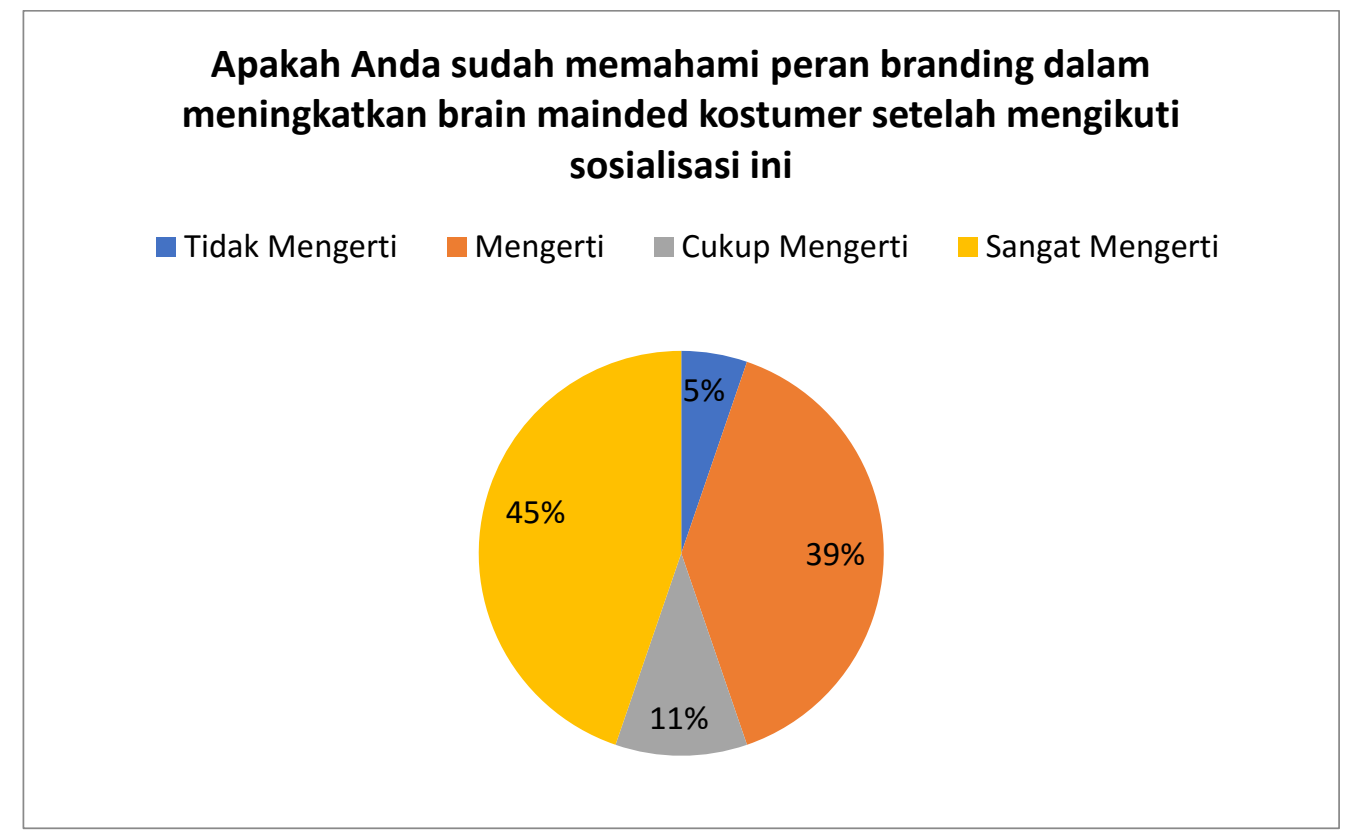

Gambar 7. Umpan balik pelaku UMKM mengenai peran branding dalam brain mainded kostumer.

\section{KESIMPULAN}

Dari kegiatan pengabdian masyarakat ini dapat disimpulkan bahwa sosialisasi branding UMKM ini merupakan bekal dan informasi yang penting untuk pelaku UMKM dalam membantu mengembangkan ide dan inovasi branding produk mereka yang selama ini masih sangat sederhana 
bahkan tidak terkonsep. Dengan melakukan inovasi branding Produk UMKM maka dapat meningkatkan citra pelaku UMKM dimata Kostumer, sehingga meningkatnya rasa kepuasan konsumen terhadap produk pelaku UMKM. Dengan adanya identitas yang kuat dari produk UMKM. Sinergi kegiatan pengabdian masyarakat ini membantu memotivasi pelaku UMKM untuk siap bersaing sehat dengan kompetitor dengan inovasi branding produk, kualitas produk dan pemasaran produk kedepannya.

\section{SARAN} yaitu:

Dengan dilaksanakannya kegiatan pengabdian masyarakat ini terdapat beberapa masukkan

1. Kepada pelaku UMKM di Binjai khususnya yang tergabung dalam organisasi IWAPI (ikatan Wanita Pengusaha Indonesia) lebih aktif untuk mengikuti workshop, pelatihan yang diselenggarkan oleh pemerintah, swasta maupun institusi.

2. Kepada pelaku UMKM terus berinovasi dan memanfaatkan teknologi sebagai sumber informasi dan mencari ide pengembangan produk agar tetap eksis.

3. Kepada para peneliti dan organisasi pemberdayaan masyarakat diharapkan saling bersinergi untuk membantu pelaku UMKM dalam mengembangkan konsep bisnis dan meningkatkan daya saing secara global khususnya dimasa pandemik ini.

\section{UCAPAN TERIMA KASIH}

1. Terima kasih kami ucapkan kepada pelaku UMKM di Binjai khususnya Organisasi IWAPI (ikatan wanita pengusaha Indonesia)

2. Terima kasih kami ucapkan kepada Manajemen dan PRPM STMIK Triguna Dharma yang telah mendukung kegiatan Tridharma pengabdian masyarakat ini berjalan dengan lancar.

\section{DAFTAR PUSTAKA}

Arianto, B. (2019). Buzzer Media Sosial dan Branding Produk UMKM Daerah Istimewa Yogyakarta. 2(1).

Entrepreneurial Mindsets \& Skill - Hadion Wijoyo - Google Buku. (n.d.). Retrieved July 27, 2021, from https://books.google.co.id

Irawan, D., \& Affan, M. W. (2020). PENDAMPINGAN BRANDING DAN PACKAGING UMKM IKATAN PENGUSAHA AISYIYAH DI KOTA MALANG. Jurnal Pengabdian Dan Peningkatan Mutu Masyarakat, 1(1), 32-36. https://doi.org/10.22219/JANAYU.V1I1.11188

Irvan, M. (2015). FASE PENGEMBANGAN KONSEP PRODUK DALAM KEGIATAN PERANCANGAN DAN PENGEMBANGAN PRODUK. Faktor Exacta, 4(3), 261-274. https://journal.lppmunindra.ac.id/index.php/Faktor_Exacta/article/view/55

Setiawati, S. D. (2019). Strategi membangun branding bagi pelaku Usaha Mikro Kecil Menengah. Jurnal Abdimas BSI: Jurnal Pengabdian Kepada Masyarakat, 2(1), 125-136. https://doi.org/10.31294/JABDIMAS.V2I1.4864 